\title{
Analysis of Physical Properties of III-Nitride Thin Films by Nanoindentation
}

\author{
SHENG-RUI JIAN, ${ }^{1}$ TE-HUA FANG, ${ }^{2}$ and DER-SAN CHUU ${ }^{1}$ \\ 1.--Institute and Department of Electrophysics, National Chiao Tung University, Hsinchu 300, \\ Taiwan. 2.-Department of Mechanical Engineering, Southern Taiwan University of Technology, \\ Tainan 710, Taiwan. E-mail: fang@mail.stut.edu.tw
}

The thin films of undoped $\mathrm{GaN}, \mathrm{GaN}: \mathrm{Si}$, and $\mathrm{Al}_{0.12} \mathrm{Ga}_{0.88} \mathrm{~N}$ on sapphire (0001) substrate using nanoindentation are investigated. The Young's modulus, hardness, and plastic energy of the films were calculated from the loading-unloading curve. The true hardness, maximum shear stress, and degree of elastic recovery are then deduced from the preceding calculated data. In addition, the loadingunloading curve clearly shows the pop-in phenomena, which can be attributed to the dislocation nucleation. To better understand the factors affecting the quality of films produced, the stress-strain relationship, which is able to reflect the quality of the fabricated films, is also analyzed using nanoindentation.

Key words: Nanoindentation, Young's modulus, hardness, maximum shear stress, plastic energy, elastic recovery, contact stress-strain

\section{INTRODUCTION}

The nitrides of the wide-bandgap III semiconductors have drawn a lot of attraction because of their applications in blue-green and ultraviolet lightemitting diodes and lasers. ${ }^{1-5}$ In addition, GaN and AlGaN are promising materials for optical and electronic devices, such as short-wavelength optical devices $^{6}$ and high-power, high-temperature transistors. ${ }^{7}$ Despite their advantages, however, there are serious problems still to be overcome in the applications of $\mathrm{GaN}$ and $\mathrm{AlGaN}$ thin films. For example, crack-free, high-quality, III-nitride thin films are difficult to grow. ${ }^{4}$

Therefore, to avoid the previously mentioned shortcomings, it is essential to have knowledge of the mechanical properties of these materials. In the past decade, the nanoindentation technique is the most frequently used to quantify thin-film properties, such as Young's modulus and hardness, within a submicron scale. ${ }^{8,9}$ In the standard indentation experiments, a Berkovich pyramid-shaped diamond tip is used to drive into the specimen and, using $\mu \mathrm{N}$ loads that produce submicrometer indentation penetration depths, allow the properties of thin films to be measured without taking away the substrate. Obviously, this technique has become an important tool for material characterizations and can readily obtain the Young's modulus and hardness of thin films under different loads from their load-displacement (P-h) curves. ${ }^{10}$

(Received July 29, 2002; accepted January 15, 2003)
One of the greatest challenges for the application of thin films is how to evaluate their mechanical properties, which can then serve as a reference for improvements in manufacturing films. The technique of nanoindentation was employed to measure the Young's modulus and hardness of some materials. ${ }^{11-14}$ However, the previous studies lacked research on mechanical properties, such as the stress-strain relationship. Because the stress-strain relationship plays an important role in understanding the inner stress of thin films, it is interesting to study the stress-strain relationship of III nitrides to obtain the true hardness, maximum shear stress, degree of elastic recovery, etc. of these materials. The plastic energy, hardness, and maximum shear stress of these thin films on a sapphire (0001) substrate will be calculated from the loading-displacement (P-h) curves. The degree of elastic recovery and the stressstrain relationship curve will also be deduced from the results of nanoindentation. These data will be useful in the design and control of the parameters of the growth process of thin films.

The primary focus of this study is to provide insight into the physical characteristics of GaN, GaN: $\mathrm{Si}$, and $\mathrm{Al}_{0.12} \mathrm{Ga}_{0.88} \mathrm{~N}$ thin films deposited by the metal-organic chemical-vapor deposition (MOCVD) method, and their properties are characterized by means of the nanoindentation technique.

\section{EXPERIMENTAL DETAILS}

To fabricate the films, a 25-nm-thick, GaN-buffer layer was first grown directly on the sapphire (0001) 
substrate by low-temperature deposition $\left(520^{\circ} \mathrm{C}\right)$. This improves the structural properties of the film. Then, GaN (2- $\mu \mathrm{m}$ thick), GaN:Si (Si doped with a carrier concentration of about $3 \times 10^{17} \mathrm{~cm}^{-3} ; 2-\mu \mathrm{m}$ thick), and $\mathrm{Al}_{\mathrm{x}} \mathrm{Ga}_{1-\mathrm{x}} \mathrm{N}$ ( $\mathrm{x}=0.12,1-\mu \mathrm{m}$ thick) films were grown on top of the buffer layer, respectively, by MOCVD at $1,120^{\circ} \mathrm{C}$, using ammonia $\left(\mathrm{NH}_{3}\right)$, trimethylgallium (TMGa), and trimethylaluminium (TMAl) as the nitrogen, gallium, and aluminium sources, respectively.

The nanoindentation test is a powerful technique for measuring thin-film mechanical properties and can provide precise measurements of the continuous indentation load, $\mathrm{P}$, down to the micro-Newton level, and the indenter-penetration depth, $h$, down to the nanometer level. An indenter-penetration depth of $<10 \%$ of the film's thickness will be used to avoid the area of interaction between the film and substrate. ${ }^{10}$ In the following, all depth-sensing indentation experiments are performed by means of the Nanoindentation System (Hysitron Triboscope, Hysitron Inc., Minneapolis, MN) and performed at room temperature. Load-controlled indentation testing followed a trapezoidal-loading profile with a hold time of typically $10 \mathrm{sec}$ at peak load. Peak loads ranged from 100 to $1,000 \mu \mathrm{N}$ at a loading rate of $10 \mu \mathrm{N} / \mathrm{sec}$. The diamond indenter was a Berkovich tip (triangular-pyramid probe) with a tip radius of $100 \mathrm{~nm}$.

\section{RESULTS AND DISCUSSION}

A typical, continuous load-displacement (P-h) curve enables us to evaluate Young's modulus and hardness. The term $\mathrm{E}_{\mathrm{r}}$, the indentation modulus, is introduced to balance the Young's modulus of the film, $\mathrm{E}_{\mathrm{f}}$, and that of the diamond indenter, $\mathrm{E}_{\mathrm{i}} \cdot{ }^{15}$

$$
\frac{1}{\mathrm{E}_{\mathrm{r}}}=\frac{2}{\mathrm{~S}} \sqrt{\frac{\mathrm{A}_{\mathrm{c}}}{\pi}}=\frac{1-\mathrm{v}_{\mathrm{f}}^{2}}{\mathrm{E}_{\mathrm{f}}}+\frac{1-\mathrm{v}_{\mathrm{i}}^{2}}{\mathrm{E}_{\mathrm{i}}}
$$

where $\mathrm{S}=\mathrm{dP} / \mathrm{dh}$ is the slope at the beginning of the unloading curve, and $\mathrm{A}_{\mathrm{c}}$ is the corresponding projected-contact area, in addition $\mathrm{v}_{\mathrm{f}}$ and $\mathrm{v}_{\mathrm{i}}$ are, respectively, Poisson's ratio of film and indenter. For diamond, $\mathrm{E}_{\mathrm{i}}=1,140 \mathrm{GPa}$ and $\mathrm{v}_{\mathrm{i}}=0.07$. As is commonly done, we assume that $\mathrm{v}_{\mathrm{f}}$ is $0.25 .^{13,14} \mathrm{As}$ the indentation depth of the diamond tip continues to increase, the load curve starts to go up until it reaches a maximum depth. After reaching the maximum depth, the tip begins to unload and return to its original position. The intersection of the tangential line of the unloading curve with the $\mathrm{x}$-axis is used to define the plastic-indentation depth, $\mathrm{h}_{\mathrm{p}}{ }^{15}$

A key problem when determining an elastic modulus from an indention experiment is how to measure the projected-contact area, $\mathrm{A}_{\mathrm{c}}$. Oliver and Pharr ${ }^{15}$ developed an improved technique for the measurement of indentation impressions. They used data directly drawn from the indentation curve and correlated the projected-contact area, $\mathrm{A}_{c}$, by an appropriate area function. The area function for an ideal
Berkovich indenter was thoroughly explored using the procedure that can be found in Ref. 15 and was employed in this study. Further discussion of the projected-contact area to contact-depth relationship is $\mathrm{A}_{\mathrm{c}}=\mathrm{F}\left(\mathrm{h}_{\mathrm{c}}\right)=24.5 \mathrm{~h}_{\mathrm{c}}^{2}$, where $\mathrm{h}_{\mathrm{c}}=\mathrm{h}_{\max }-0.72 \frac{\mathrm{P}_{\max }}{\mathrm{S}_{\max }}$ is the contact depth, $\mathrm{h}_{\max }$ is the maximum depth, $\mathrm{P}_{\max }$ is the maximum load, and $\mathrm{S}_{\max }$ is the slope of the unloading curve at the maximum load. The analysis software of the Hysitron TriboScope System has the capabilities to perform the automatic calculation of nanomechanical properties, automated correction for tip calibration, and so on. Our experiment procedures also followed the TriboScope software package suggested calibration standards. Hardness $(\mathrm{H})$ is determined by applying a maximum indentation load, $\mathrm{P}_{\max }$, to a probe of a prescribed sharp Berkovich tip (which is a three-sided pyramidal-diamond tip) driving it into the films. Thus, $\mathrm{H}$ is given by dividing $\mathrm{P}_{\max }$ by the projectedcontact area, ${ }^{15}$ i.e.,

$$
\mathrm{H}=\frac{\mathrm{P}_{\max }}{\mathrm{A}_{\mathrm{c}}}
$$

The Young's modulus of deposited films can be derived during the nanoindentation process by Eq. 1, as mentioned previously. The Young's modulus changes with the relative penetration depth, indicating that the indenter deforms not only the film but also the substrate, and can be measured because of the large indentation depth with the appreciable substrate effects. The Young's modulus and hardness of GaN, GaN:Si, and $\mathrm{Al}_{0.12} \mathrm{Ga}_{0.88} \mathrm{~N}$ were calculated under loads of $1-3 \mathrm{mN}$ (Fig. 1). The Young's modulus of GaN, GaN:Si, and $\mathrm{Al}_{0.12} \mathrm{Ga}_{0.88} \mathrm{~N}$ are 274.35-355.5 $\mathrm{GPa}, 232.27-262.06 \mathrm{GPa}$, and 272.14-358.33 GPa,

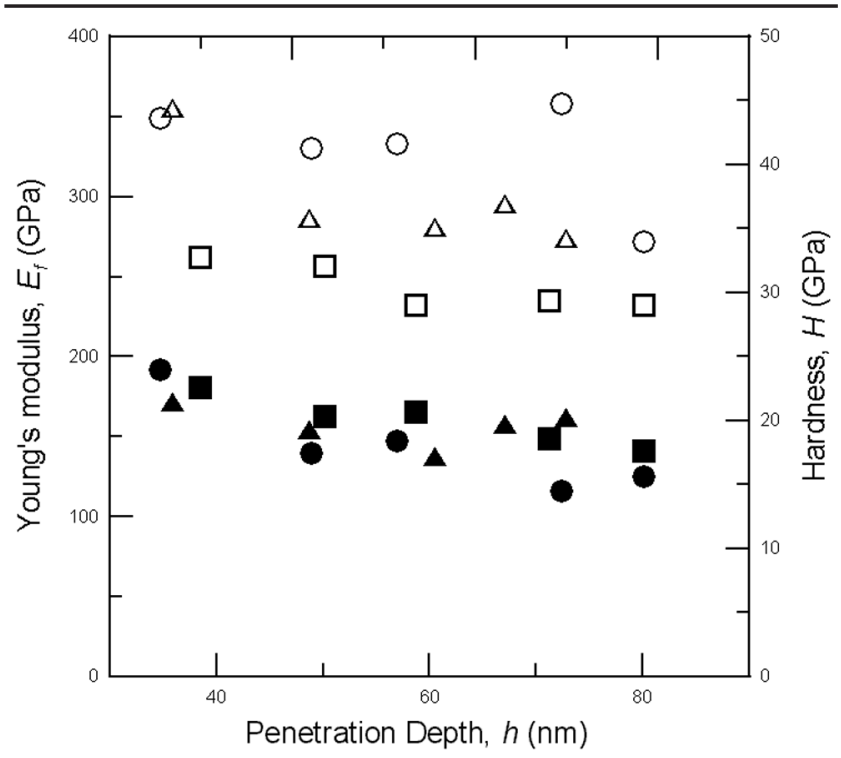

Fig. 1. The Young's modulus, $E_{f}: G a N(\triangle)$, GaN:Si ( $\square$ ) and $A_{0.12}$ $\mathrm{Ga}_{0.88} \mathrm{~N}(\bigcirc)$ films measured as a function of the penetration depth, and for hardness, $\mathrm{H}: \mathrm{GaN}(\boldsymbol{\Delta}), \mathrm{GaN}: \mathrm{Si}(\boldsymbol{\square})$, and $\mathrm{Al}_{0.12} \mathrm{Ga}_{0.88} \mathrm{~N}(\bullet)$. 
respectively. Hardness is well suitable for measuring of the film's plastic behavior, just the same as the modulus to the film's elastic response. The corresponding hardness values are 17.21-21.47 $\mathrm{GPa}$, 17.61-22.62 GPa, and 14.48-24.00 GPa, respectively. The results of the GaN thin film are similar to the previous studies of $\mathrm{Yu}$ et al. ${ }^{11}$ and Kucheyev et al., ${ }^{12}$ but differ from the bulk-crystal properties of $\mathrm{GaN}$ (Nowak et $\mathrm{al}^{13}{ }^{13}$. The experimental loaddisplacement curves on the thin films each show a pop-in at a critical load. Such discontinuities or load excursions are observed mainly on oxidized or electropolished films. ${ }^{16}$ These events are observed frequently on smooth surfaces, but not on very rough surfaces.

The discontinuities, or pop-in events, in the experimental load-displacement plots, can be seen in Fig. 2a-c for $\mathrm{GaN}, \mathrm{GaN}: \mathrm{Si}$, and $\mathrm{Al}_{0.12} \mathrm{Ga}_{0.88} \mathrm{~N}$, respec-
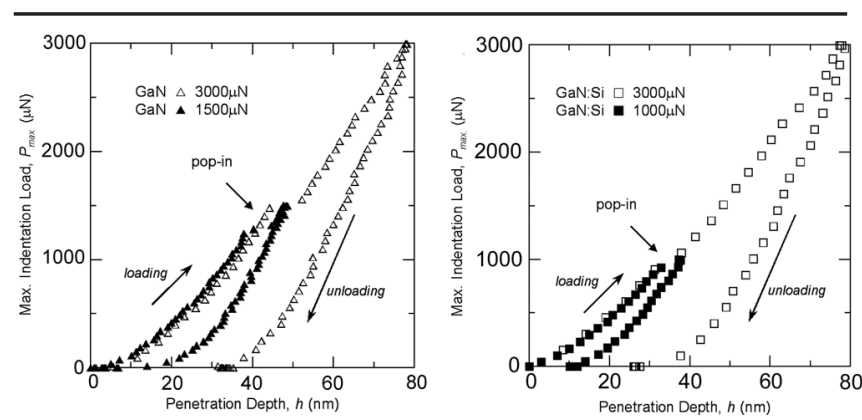

a

b
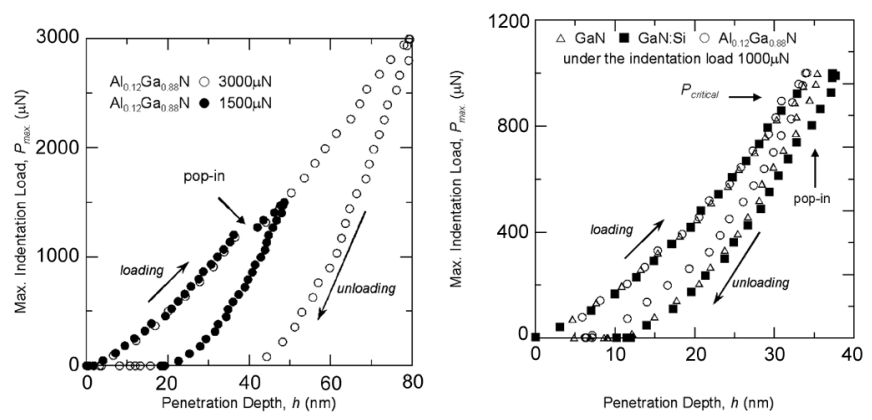

d

Fig. 2. The schematic loading-unloading curves to illustrate the popin event of (a) $\mathrm{GaN}$, (b) $\mathrm{GaN}: \mathrm{Si}$, and (c) $\mathrm{Al}_{0.12} \mathrm{Ga}_{0.88} \mathrm{~N}$ films; (d) shows the pop-in event in the three films at a load of $1,000 \mu \mathrm{N}$. tively. The GaN film was doped with a concentration of $\mathrm{Si}\left(3 \times 10^{17} \mathrm{~cm}^{-3}\right)$ to increase the electron-hole pairs. Although this gives the film better illuminant qualities, it may also be detrimental to the mechanical properties. The latter implies that a concentration of doped impurities have the same effect as defects in the microstructure. The pop-in events occurring during the nanoindentation processes are related to the dislocations and defects. According to previous studies, ${ }^{12,14,17}$ we defined the discontinuity phenomena, which occur at the P-h curves, as the "pop-in" events. Indeed, the plastic-deformation processes are very complex, and it is necessary to understand what happens with the mechanisms as the indenter-diamond tip pushes into the surface. Additionally, Kucheyev et al. ${ }^{18}$ and Twigg et al. ${ }^{19}$ also observed this phenomenon in the loading-unloading curves of single-crystal $\mathrm{ZnO}$ and polycrystalline alumina by nanoindentation, respectively. At the onset of the irreversible deformation, interstitial-dislocation loops nucleate. This phenomenon is probably related to the fact that the plastic deformation is dominated by pop-in events. ${ }^{17}$ The nucleation of dislocation causes the microstructure transformation and slipband behavior on the film surface that was observed using cross-section, transmission electron microscopy technology under loads. ${ }^{20}$ In our study, the depths of the pop-in events for $\mathrm{GaN}, \mathrm{GaN}: \mathrm{Si}$, and $\mathrm{Al}_{0.12} \mathrm{Ga}_{0.88} \mathrm{~N}$ thin films corresponding to the loads of $1.2-1.5 \mathrm{mN}$, $0.9-1.2 \mathrm{mN}$, and $1.2-1.4 \mathrm{mN}$ were $39-45 \mathrm{~nm}, 32-$ $40 \mathrm{~nm}$, and $36-48 \mathrm{~nm}$, respectively.

It has been identified that the processes responsible for this pop-in event are associated with the dislocation nucleation. Knowing the critical load, an estimation of the maximum shear stress necessary to create a dislocation can be made as follows. The maximum elastic-shear stress, $\tau_{\max }$, is given by the relation: ${ }^{20}$

$$
\tau_{\max }=0.31\left(\frac{6 \mathrm{P}_{\text {critical }} \mathrm{E}_{\mathrm{f}}^{2}}{\pi^{3} \mathrm{R}^{2}}\right)^{1 / 3}
$$

where $\mathrm{P}_{\text {critical }}$ is the critical load at which the pop-in occurs during the nanoindentation process. Using spherical geometry, $\tau_{\max }$ is easily evaluated from this critical load and the film's properties. The experimental results are shown in Table I. The critical load

Table I. Max. Shear Stress, $\tau_{\max }$, vs. the Max. Indentation Load, $\mathbf{P}_{\max }$ of Thin Films*

\begin{tabular}{|c|c|c|c|c|c|c|}
\hline \multirow[b]{2}{*}{ Load $(\mu \mathbf{N})$} & \multicolumn{2}{|c|}{ GaN } & \multicolumn{2}{|c|}{ GaN:Si } & \multicolumn{2}{|c|}{$\mathrm{Al}_{0.12} \mathbf{G a}_{0.88} \mathbf{N}$} \\
\hline & $\mathbf{P}_{\text {critical }}$ & $\tau_{\max }$ & $\mathbf{P}_{\text {critical }}$ & $\tau_{\max }$ & $\mathbf{P}_{\text {critical }}$ & $\tau_{\max }$ \\
\hline 1,000 & - & - & - & - & 976.25 & 2.49 \\
\hline 1,500 & $1,289.49$ & 2.90 & $1,082.69$ & 2.55 & $1,202.14$ & 3.12 \\
\hline 2,000 & $1,294.93$ & 2.87 & $1,225.19$ & 2.48 & $1,290.18$ & 3.21 \\
\hline 2,500 & $1,457.57$ & 3.09 & $1,034.58$ & 2.36 & $1,398.89$ & 3.46 \\
\hline 3,000 & $1,542.09$ & 2.99 & 962.44 & 2.29 & $1,286.88$ & 2.81 \\
\hline
\end{tabular}

*Unit of $\tau_{\max }$ is GPa. 
of the three films is shown in Fig. $2 \mathrm{~d}$ and Table I. Note, under a load of $1,000 \mu \mathrm{N}$, only the GaN:Si thin film shows a maximum shear stress. This shows that the existence of the pop-in event corresponds to the dislocation nucleation. To sum up, the pop-in event corresponds to a plastic behavior.

To calculate the value of true hardness, $\mathrm{H}_{\mathrm{t}},{ }^{21}$ we used the P-h curves to determine the plastic energy, $\mathrm{U}_{\mathrm{r}}$ (the area between the load and unload curves), and $\mathrm{P}_{\text {max }}$ :

$$
\mathrm{U}_{\mathrm{r}}=\frac{1}{3} \sqrt{\frac{1}{\alpha_{0} \tan ^{2} \varphi}} \frac{1}{\sqrt{\mathrm{H}_{\mathrm{t}}}} \mathrm{P}_{\max }^{3 / 2}
$$

where $\alpha_{0}$ and $\varphi$ are the geometrical constant and the semiapex angle of the indenter, respectively $\left(\alpha_{0}=\right.$ $3 \sqrt{3}$ and $\varphi=65.3^{\circ}$ for the triangular-tip indenter). The nanoindentation process promotes the deformation of materials. Both the elastic- and plastic-deformation energies of the materials increase with increasing load, but the elastic energy increases slower than the plastic energy.

The maximum indentation load increased with increasing plastic energy, as shown in Fig. 3. It can be clearly seen that increasing the load caused the in-

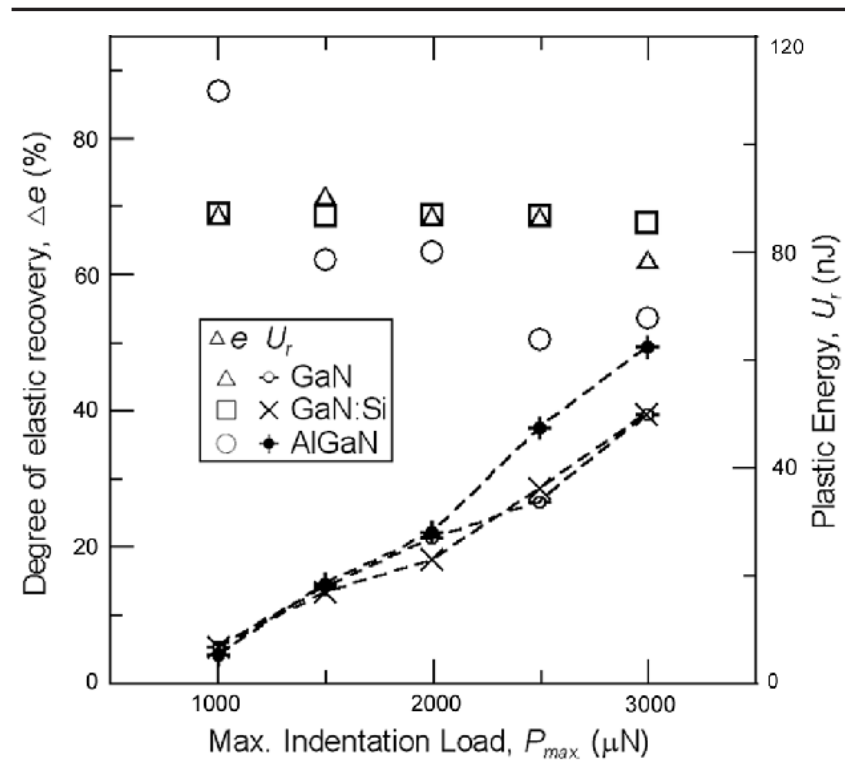

Fig. 3. The plastic energy, $U_{r}$, and degree of elastic recovery, $\triangle e$, versus the maximum indentation load, $\mathrm{P}_{\max }$. creasing deformation corresponding to plastic energy. In addition, the true hardness was calculated in Table II.

The elastic recovery of thin films is revealed by the plastic deformation and can be used for further investigation of recovery in the indentation process. The degree of elastic recovery varies with the properties and microstructures of materials. Thus, it is not an absolute value; instead, it is just a reference index. From the experimental loading-unloading curves, we can evaluate the degree of elastic recovery $(\Delta \mathrm{e})^{19}$ on unloading the indenter:

$$
\Delta \mathrm{e}=\frac{\mathrm{h}_{\max }-\mathrm{h}_{\mathrm{rp}}}{\mathrm{h}_{\max }}
$$

where $h_{\max }$ is the maximum depth, and $h_{r p}$ is the residual plastic depth after unloading.

The plastic energy increases with the load, but the elastic recovery decreases theoretically. Figure 3 shows that the ranges of the degree of elastic recovery of thin films under three different maximum loads of $(999 \pm 0.2-2988 \pm 2.4) \mu \mathrm{N}$ are about 50 $85 \%$, and a high resistance against crack formation even at a strain of greater than or equal to $15-50 \%$. As can be seen, the higher value of $\Delta \mathrm{e}$ points out that the deposited films have the ability to bear local stress caused by a single impact without a lot of microcrack and damage events, in general, by means of the MOCVD method to grow the III-nitride thin films, and the moderation of the stress problem by the buffer layer. ${ }^{22}$ According to the ratio of elastic recovery analysis, we deduced that the reduction in the stress effect may be caused by the buffer layer because it influenced the thin film to maintain $\Delta \mathrm{e}$ at about $15-50 \%$ as the indentation loads increased. As is clearly seen in Fig. 3, the values of $\Delta \mathrm{e}$ have no obvious variation when the indentation load is increased. This suggests an improvement in the growth process of thin films, enabling them to meet high performance demands, such as an ability to bear a greater load.

The lattice-mismatch phenomenon of thin films always occurs in the growth process. The stress-strain analysis that reveals the local strain in the thin films is very useful in improving the growth process, e.g., by decreasing lattice mismatch and the crack-free phenomena. So as to better understand the mechanism of plastic deformation on deposited films, the

Table II. The True Hardness Value of GaN, GaN:Si, and $\mathrm{Al}_{0.12} \mathrm{Ga}_{0.88} \mathrm{~N}$ Films Measured

\begin{tabular}{|c|c|c|c|}
\hline Materials & \multicolumn{3}{|c|}{ True Hardness (GPa) } \\
\hline GaN & 49.12 & $53.6^{9}$ & $56.3^{9}$ \\
\hline GaN:Si & 53.31 & - & - \\
\hline $\mathrm{Al}_{0.12} \mathrm{Ga}_{0.88} \mathrm{~N}$ & 45.74 & - & - \\
\hline Sapphire & - & $26.92^{8}$ & - \\
\hline
\end{tabular}
by Different Indentation Loads 


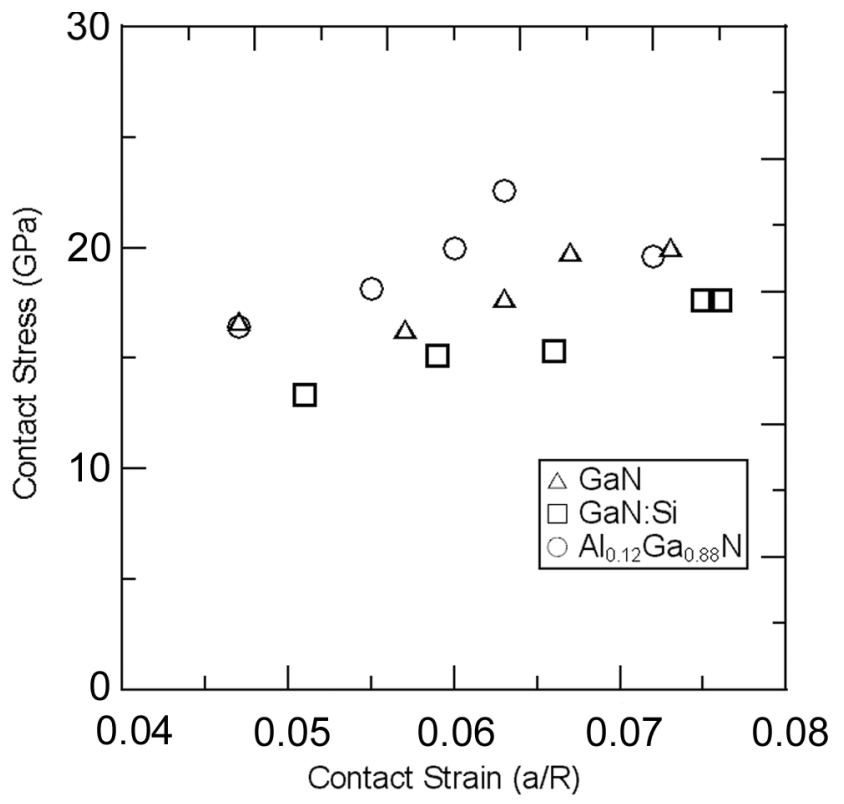

Fig. 4. The contact stress-strain relationship of the GaN, GaN:Si, and $\mathrm{Al}_{0.12} \mathrm{Ga}_{0.88} \mathrm{~N}$ radius of the contact area, a.

radius, a, of the contact area to determine the stress is calculated by using the Hertzian equation: ${ }^{23}$

$$
\mathrm{a}=\left(\frac{3 \mathrm{PR}}{4 \mathrm{E}_{\mathrm{r}}}\right)^{1 / 3}
$$

The contact stress-strain relationship of thin films is shown in Fig. 4. This analysis revealed that the local strain on deposited films can be useful in improving the quality of the films and also in recognizing the deformation mechanisms of nanometer scale under the micro-Newton level indentation loads. The value of stress increases with the indentation loads. The larger stress causes the larger strain and deformation of thin films that subsequently leads to yielding behavior. It can be seen that the value of the contact stress of the $\mathrm{Al}_{012} \mathrm{Ga}_{0.88} \mathrm{~N}$ thin film decreases after $23 \mathrm{GPa}$. Table I shows that the critical load of $\mathrm{Al}_{0.12} \mathrm{Ga}_{0.88} \mathrm{~N}$ is about $1.39 \mathrm{mN}$, which confirms that the yielding point takes place at $23 \mathrm{GPa}$.

\section{CONCLUSIONS}

In summary, continuous depth-sensitive recording nanoindentation measurements provide a convenient way of investigating the mechanical properties of thin films. Using a nanoindentation technique, hardness and Young's modulus were measured in three thin films. The observation manifests that the increasing of the indentation loads will decrease the hardness and Young's modulus. During Berkovich nanoinden- tation tests, discontinuities, or pop-in events, were found in the indentation load-displacement curves and can be attributed to the dislocation nucleation. In this study, the stress-strain analysis of thin films yields the reference data necessary to improve the quality of thin films and an effective growth process. Moreover, this experimental data confirms our evaluation of the yielding point of $\mathrm{Al}_{0.12} \mathrm{Ga}_{0.88} \mathrm{~N}$.

\section{ACKNOWLEDGEMENTS}

The authors acknowledge the partial support of this work by the National Science Council, Republic of China, under Grant Nos. NSC 91-2112-M-009-012 and NSC90-2218-E-218-011.

\section{REFERENCES}

1. S. Nakamura, M. Senoh, and T. Mukai, Jpn. J. Appl. Phys. 32, L8 (1993).

2. S. Nakamura, T. Mukai, and M. Senoh, Appl. Phys. Lett. 64, 1687 (1994).

3. N. Mohammad, A.A. Salvador, and H. Morkoc, Proc. IEEE 83, 1306 (1995).

4. S. Nakamura, M. Senoh, S. Nagahana, N. Iwasa, T. Yamada, T. Matsushita, H. Kiyoku, and Y. Sugimoto, Appl. Phys. Lett. 69, 4056 (1996).

5. S. Nakamura and G. Fasol, The Blue Laser Diode (Berlin: Springer, 1997), pp. 1-5.

6. A. Osinsky, S. Gangopadhyay, J.W. Yang, R. Gaska, D. Kuksenkov, H. Temkin, I.K. Shmagin, Y.C. Chang, J.F. Muth, and R.M. Kolbas, Appl. Phys. Lett. 72, 551 (1998).

7. M.S. Shur, Solid-State Electron. 42, 2131 (1998).

8. N.R. Moody, W.W. Gerberich, N. Burnham, and S.P. Baker, Fundamentals of Nanoindentation and Nanotribology (Warrendale, PA: Materials Research Society, 1998), pp. 3-45.

9. C.M. Yang, Mater. Chem. Phys. 41, 295 (1995).

10. T.Y. Tsui and G.M. Phraa, J. Mater. Res. 14, 292 (1999).

11. G. Yu, H. Ishikawa, T. Egawa, T. Soga, J. Watanable, T. Jimbo, and M. Umeno, J. Cryst. Growth 189/190, 701 (1998).

12. S.O. Kucheyev, J.E. Bradby, J.S. Williams, C. Jagadish, M. Toth, M.R. Phillips, and M.V. Swain, Appl. Phys. Lett. 77, 3373 (2000).

13. R. Nowak, M. Pessa, M. Suganuma, M. Leszczynski, I. Grzegory, S. Porowski, and F. Yoshida, Appl. Phys. Lett. 75, 2070 (1999).

14. D. Cáceres, I. Vergara, R. González, E. Monory, F. Calle, E. Muñoz, and F. Omnès, J. Appl. Phys. 86, 6773 (1999).

15. W.C. Oliver and G.M. Pharr, J. Mater. Res. 7, 1564 (1992).

16. A. Strojny, E.T. Lilleodden, G. Wang, J.V. Sivertsen, and W.W. Gerberich, Mater. Res. Soc. Symp. Proc. 436, 281 (1997).

17. T.F. Page, W.C. Oliver, and C.T. McHargue, J. Mater. Res. 7, 450 (1992).

18. S.O. Kucheyev, J.E. Bradby, J.S. Williams, C. Jagadish, and M.V. Swain, Appl. Phys. Lett. 80, 956 (2002).

19. P.C. Twigg, F.L. Riley, and S.G. Roberts, J. Mater. Sci. 37, $845(2002)$

20. J.E. Bradby, S.O. Kucheyev, J.S. Williams, J. Wong-Leung, M.V. Swain, P. Munroe, G. Li, and M.R. Phillips, Appl. Phys. Lett. 80, 383 (2002).

21. M. Sakai, Acta Metall. Mater. 41, 1759 (1993).

22. M.H. Kin, Y.G. Do, H.C. Kang, D.Y. Noh, and S.J. Park, Appl. Phys. Lett. 79, 2713 (2001).

23. K.L. Johnson, Contact Mechanics (Cambridge, U.K.: Cambridge University Press, 1985), p. 93. 